\title{
Simulation-Based Training in Flexible Bronchoscopy and Endobronchial Ultrasound-Guided Transbronchial Needle Aspiration (EBUS-TBNA): A Systematic Review
}

\author{
Therese Maria Henriette Naur $^{\mathrm{a}}$ Philip Mørkeberg Nilsson ${ }^{\mathrm{a}}$ Pia Iben Pietersen ${ }^{\mathrm{b}}$ \\ Paul Frost Clementsen ${ }^{a, c}$ Lars Konge ${ }^{a}$ \\ ${ }^{a}$ Copenhagen Academy for Medical Education and Simulation (CAMES), Rigshospitalet, University of \\ Copenhagen and the Capital Region of Denmark, Copenhagen, ${ }^{b}$ Department of Respiratory Medicine, \\ Odense University Hospital, Odense, and ' Department of Internal Medicine, Zealand University Hospital, \\ Roskilde, Denmark
}

\section{Keywords}

Simulation - Training · Flexible bronchoscopy ·

Endobronchial ultrasound · Bronchoscopy education

\begin{abstract}
Background: The use of simulators in a training programme for technically challenging procedures has the advantages of lowering the risk of patient complications while helping the trainees with the initial part of their learning curve. Objectives: The aim of this study was to perform a systematic review of simulation-based training in flexible bronchoscopy and endobronchial ultrasound (EBUS). Methods: We identified 1,006 publications in the PubMed database and included publications on flexible bronchoscopy below the carina and EBUS involving hands-on simulation-based training. Publications were excluded if they were written in languages other than English, if paediatric airways were involved or if they were not journal articles. The screening process was performed by 2 individuals, and a third reviewer made the final decision in case of disagreement. Results: We included 30 publications. The studies included participants
\end{abstract}

\section{KARGER}

(C) 2017 S. Karger AG, Basel of varying experience and most commonly used a virtual reality simulator as a training modality. Assessment of the participants' skills was based on simulator metrics or on an assessment tool. Some studies included performance on patients for assessment of the operator after training on a simulator. Conclusions: Simulation-based training was demonstrated to be more efficient than the traditional apprenticeship model. Physical models and virtual reality simulators complement each other. Simulation-based education should be based on a mastery learning approach and structured as directed self-regulated learning in a distributed training programme.

(c) 2017 S. Karger AG, Basel

\section{Introduction}

Flexible bronchoscopy with biopsy and endobronchial ultrasound-guided transbronchial needle aspiration (EBUS-TBNA) are important invasive procedures for the diagnosis and staging of patients with lung cancer [1] and other diseases. The procedures are technically chal-

Therese Maria Henriette Naur

Copenhagen Academy for Medical Education and Simulation (CAMES) Rigshospitalet

DK-2100 Copenhagen (Denmark)

E-Mail therese.naur@gmail.com 
Fig. 1. Literature search strategy, PRISMA guidelines. EBUS, endobronchial ultrasound.

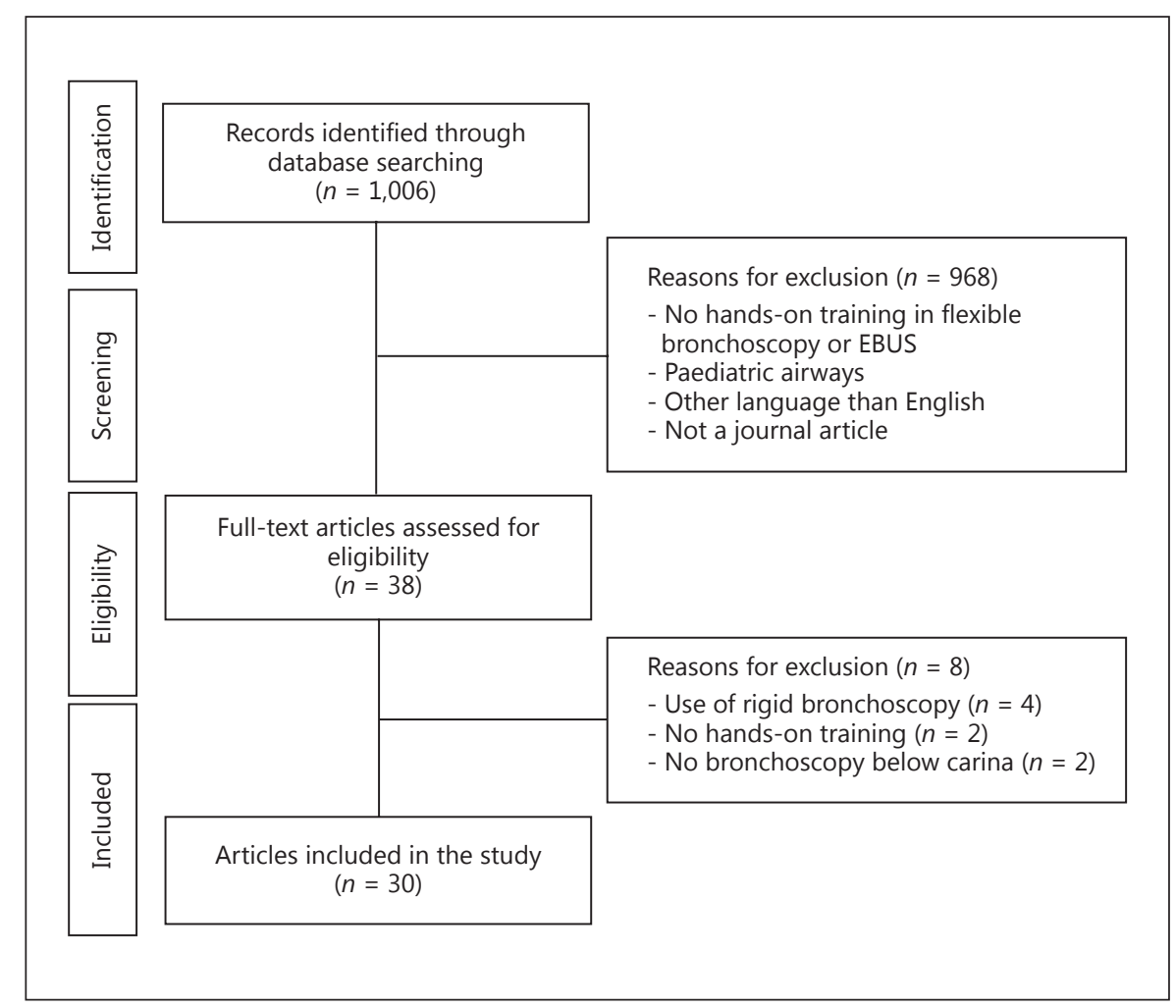

lenging, and the diagnostic yield increases with experience $[2,3]$. Invasive procedures are traditionally taught using the apprenticeship model, where trainees practice on patients supervised by an experienced colleague, but this method of teaching increases the rate of patient complications, the procedure time, and the amount of sedation used [4]. An alternative approach to training on patients is simulation-based training, where trainees practice skills in a controlled environment that is inherently patient safe. The idea of using simulators, including virtual reality, synthetic phantoms, and cadaveric models, is to help the learner with the initial part of the learning curve [5], thus reducing complications due to inexperience and allowing the trainee to learn from errors in a forgiving and stress-free environment [6-8]. Medical education, including simulation-based training, should be based on best available evidence, with standards similar to those that guide patient treatment. The aim of this study was to provide a systematic overview of the available literature regarding simulationbased training in flexible bronchoscopy and EBUSTBNA and to explore the optimal training programme and assessment method.

\section{Materials and Methods}

This systematic review was conducted in accordance with the Preferred Reporting Items for Systematic Reviews and MetaAnalyses (PRISMA) guidelines [9]. We identified a total of 1,006 publications from the PubMed database using the following search string: (bronchoscopy OR endobronchial ultrasound OR EBUS) AND (simulat* OR training). Two independent reviewers searched the publications for eligibility. We included publications on flexible bronchoscopy below the carina and EBUS involving hands-on simulation-based training on virtual reality simulators, synthetic phantoms/models and/or cadaveric models. Publications were excluded if they were written in languages other than English, if the training was performed on paediatric airways or if the publication was an expert opinion, a commentary, a poster or similar. The full text of a publication was screened when necessary. In the event of disagreement between the 2 reviewers, a third reviewer made the final decision regarding inclusion. Based on this method, 38 publications were selected for full-text review. Several studies were subsequently identified that did not fulfil inclusion criteria: hands-on simulation-based training was not included in 2 publications, the bronchoscopy training was done with a rigid bronchoscope in 4 publications and the training did not include bronchoscopy below the carina (but rather only training in intubation) in 2 publications. Therefore, these 8 publications were excluded, resulting in 30 remaining publications (Fig. 1). As a final step, we reviewed the reference lists of the 30 publications to search for missed studies. No additional publications were identified with this method. 
Table 1. Publications on flexible bronchoscopy: study characteristics

\begin{tabular}{|c|c|c|c|c|c|c|c|}
\hline First author [ref.], year & Category & Modality & $\begin{array}{l}\text { Study } \\
\text { design }\end{array}$ & $\begin{array}{l}\text { Partici- } \\
\text { pants, } n\end{array}$ & $\begin{array}{l}\text { Competence level of } \\
\text { participants }\end{array}$ & Assessment of skill ${ }^{\mathrm{a}}$ & Outcome measures \\
\hline Bjerrum [10], 2016 & $\mathrm{TM}$ & VR & RCT & 20 & trainees & simulator metrics & $\begin{array}{l}\text { performance on } \\
\text { simulator }\end{array}$ \\
\hline Byrne [11], 2016 & SIM & manikin & des & - & $\begin{array}{l}\text { "experienced } \\
\text { bronchoscopists" }\end{array}$ & none & expert opinion \\
\hline Chen [12], 2016 & SIM & $\begin{array}{l}\text { human } \\
\text { cadaver }\end{array}$ & des & 4 & $\begin{array}{l}\text { "experienced } \\
\text { bronchoscopists" }\end{array}$ & none & expert opinion \\
\hline Colella [13], 2015 & AT & VR & NR & 29 & MDs, students & motion analysis & $\begin{array}{l}\text { performance on } \\
\text { simulator }\end{array}$ \\
\hline Pastis [14], 2014 & SIM & VR & val & 20 & MDs, trainees & simulator metrics & $\begin{array}{l}\text { performance on } \\
\text { simulator, expert } \\
\text { opinion, trainee } \\
\text { opinion }\end{array}$ \\
\hline Bjerrum [15], 2014 & TM & VR & RCT & 36 & students & simulator metrics & $\begin{array}{l}\text { performance on } \\
\text { simulator }\end{array}$ \\
\hline Krogh [16], 2013 & SIM & VR & RCT & 20 & students & blinded assessment & $\begin{array}{l}\text { performance on } \\
\text { simulator }\end{array}$ \\
\hline Konge [17], 2011 & AT & VR & val & 42 & MDs, Students & $\begin{array}{l}1 \text { non-blinded, } \\
2 \text { blinded raters }\end{array}$ & $\begin{array}{l}\text { performance on } \\
\text { simulator }\end{array}$ \\
\hline Konge [18], 2011 & SIM & VR & val & 30 & MDs & simulator metrics & $\begin{array}{l}\text { performance on } \\
\text { simulator, expert } \\
\text { opinion }\end{array}$ \\
\hline Colt [19], 2011 & $\mathrm{AT}$ & manikin & NR & 24 & trainees & 1 non-blinded rater & $\begin{array}{l}\text { performance on } \\
\text { simulator }\end{array}$ \\
\hline Wahidi [20], 2010 & $\mathrm{TM}$ & VR, patients & NR & 41 & trainees & 1 non-blinded rater & $\begin{array}{l}\text { performance on } \\
\text { patients }\end{array}$ \\
\hline Davoudi [21], 2010 & SIM & VR, manikin & NR & 44 & MDs, other & - & expert opinion \\
\hline Goldberg [22], 2009 & SIM & animal & NR & 12 & MDs, Trainees & - & $\begin{array}{l}\text { expert and trainee } \\
\text { opinion }\end{array}$ \\
\hline Deutsch [23], 2009 & SIM & $\begin{array}{l}\text { manikin, VR, } \\
\text { animal }\end{array}$ & NR & 36 & trainees & - & trainee opinion \\
\hline Davoudi [24], 2008 & AT & VR & val & 22 & $\begin{array}{l}\text { MDs, trainees, } \\
\text { students }\end{array}$ & 2 non-blinded raters & $\begin{array}{l}\text { performance on } \\
\text { simulator }\end{array}$ \\
\hline Di Domenico [25], 2007 & SIM & manikin & des & - & - & - & expert opinion \\
\hline Chen [26], 2006 & SIM & VR & val & 30 & MDs & simulator metrics & $\begin{array}{l}\text { performance on } \\
\text { simulator, expert } \\
\text { opinion }\end{array}$ \\
\hline Agrò [27], 2005 & TM & $\begin{array}{l}\text { model, } \\
\text { manikin }\end{array}$ & NR & 5 & MDs & procedural time & $\begin{array}{l}\text { performance on } \\
\text { simulator }\end{array}$ \\
\hline Martin [28], 2004 & SIM, TM & model & NR & 40 & MDs, trainees, other & 2 blinded raters & $\begin{array}{l}\text { performance on } \\
\text { participants }\end{array}$ \\
\hline Blum [29], 2004 & TM & VR & RCT & 13 & trainees & $\begin{array}{l}1 \text { non-blinded rater, } \\
\text { self-evaluation }\end{array}$ & $\begin{array}{l}\text { performance on } \\
\text { patients }\end{array}$ \\
\hline Moorthy [30], 2003 & SIM & VR & val & 18 & $\begin{array}{l}\text { "novices," "experienced } \\
\text { bronchoscopists" }\end{array}$ & simulator metrics & $\begin{array}{l}\text { performance on } \\
\text { simulator }\end{array}$ \\
\hline Ost [31], 2001 & SIM, TM & VR & $\begin{array}{l}\text { val, } \\
\text { RCT }\end{array}$ & 28,6 & MDs, trainees, other & $\begin{array}{l}\text { simulator metrics, } \\
1 \text { non-blinded rater }\end{array}$ & $\begin{array}{l}\text { performance on } \\
\text { simulator, } \\
\text { performance on } \\
\text { patients }\end{array}$ \\
\hline Colt [32], 2001 & TM & VR, manikin & NR & 9 & trainees & $\begin{array}{l}\text { simulator metrics, } \\
1 \text { non-blinded rater }\end{array}$ & $\begin{array}{l}\text { performance on } \\
\text { simulator }\end{array}$ \\
\hline
\end{tabular}

TM, studies comparing training methods; SIM, studies developing and/or exploring simulation equipment; AT, studies developing and/or exploring assessment tools; VR, virtual reality simulator; manikin, anatomical simulator of synthetic material; model, non-anatomical model simulator; RCT, randomized controlled trial; des, descriptive study; NR, non-randomized; val, validity study; trainee, resident/fellow; MD, physician/specialist; students, medical students. ${ }^{a}$ Method of assessment if the study involved an assessment of skill.

Simulation-Based Training in Flexible Bronchoscopy and EBUS-TBNA
Respiration 2017;93:355-362

DOI: $10.1159 / 000464331$ 
Table 2. Publications on endobronchial ultrasound: study characteristics

\begin{tabular}{llllllll}
\hline $\begin{array}{l}\text { First author [ref.], } \\
\text { year }\end{array}$ & Category & Modality & $\begin{array}{l}\text { Study } \\
\text { design }\end{array}$ & $\begin{array}{l}\text { Partici- } \\
\text { pants, } n\end{array}$ & $\begin{array}{l}\text { Competence level } \\
\text { of participants }\end{array}$ & Assessment of skilla & Outcome measures \\
\hline Konge [33], 2015 & AT, TM & VR, patients & val, RCT & 18 & MDs & 3 blinded raters & performance on patients \\
Stather [34], 2013 & TM & VR & NR & 14 & trainees & simulator metrics & performance on simulator \\
Konge [35], 2013 & AT & VR & val & 22 & MDs & simulator metrics & performance on simulator \\
Stather [36], 2012 & TM & VR, animal models & RCT & 12 & MDs, trainees & simulator metrics & performance on simulator \\
Stather [37], 2012 & TM & VR, patients & NR & 8 & trainees & 1 non-blinded rater & performance on patients \\
Stather [38], 2011 & TM & VR, patients & NR & 13 & trainees & simulator metrics & performance on simulator \\
Stather [39], 2011 & SIM & VR & val & 22 & MDs, trainees & simulator metrics & performance on simulator \\
\hline
\end{tabular}

AT, studies developing and/or exploring assessment tools; TM, studies comparing training methods; SIM, studies developing and/or exploring simulation equipment; VR, virtual reality simulator; val, validity study; RCT, randomized controlled trial; NR, non-randomized; MD, physician/specialist; trainee, resident/fellow. ${ }^{\text {a }}$ Method of assessment if the study involved an assessment of skill.

\section{Results}

A total of 30 publications [10-39] were included. We divided them into 2 groups: publications on flexible bronchoscopy $(n=23)$ and publications on EBUS $(n=7)$. Tables 1 and 2 show key features.

In total, there were 10 validation studies $[14,17,18,24$, $26,30,31,33,35,39], 7$ randomized trials $[10,15,16,29$, $31,33,36]$ and 3 descriptive studies $[11,12,25]$. The remaining studies $[13,19-23,27,28,32,34,37,38]$ either tested various training methods $[20,27,28,32,34,37,38]$, simulators $[21-23,28]$ or a new approach to skills assessment $[13,19]$.

The study participants varied in their experience level and included medical students and postgraduate residents or fellows with little or no experience in flexible bronchoscopy or EBUS, as well as experts in one or both fields. Four studies included other healthcare professionals $[21,28,30,31]$.

The most common modality for training was virtual reality simulators, most frequently consisting of a proxy flexible bronchoscope that could be inserted into an interface, as well as a computer with simulation software that could display a virtual image of the bronchi. Some of the simulators also had a tactile feedback mechanism and/or the ability to simulate normal human activities (i.e., breathing, coughing, etc.) for heightening the realism. Two studies described building a low-fidelity model out of inexpensive materials $[11,25]$. Other studies used animal cadavers or manikins that replicated lung anatomy to simulate a realistic bronchial tree. Some included the use of animal models $[22,23,36]$, and 1 study used a human cadaver [12]. Table 3 shows an overview of the simulators used in the publications.

\section{Flexible Bronchoscopy}

We found a total of 23 publications on simulationbased training in flexible bronchoscopy (Table 1).

\section{Studies Developing and/or Exploring Simulation}

Equipment

Thirteen studies either gathered validity evidence for a simulation-based test $[14,18,26,30,31]$, compared different simulators $[21,23,28]$ or described the effectiveness of alternative simulators, e.g., a human cadaver, a portable simulator or low-cost models $[11,12,16,22,25]$. When gathering validity evidence, the outcome measure that consistently differentiated novices from experts was procedure time. Other reported outcome measures were segments entered, number of bronchial wall collisions and segments correctly or incorrectly identified.

\section{Studies Developing and/or Exploring Assessment} Tools

Four studies explored assessment tools. Davoudi et al. [24] gathered validity evidence for the Bronchoscopy Skills and Tasks Assessment Tool (BSTAT) and the Bronchoscopy Step-by-Step Evaluation Tool (BSET). Konge et al. [17] developed a new assessment tool and gathered validity evidence for its ability to differentiate between varying levels of experience beyond the typical standards of novices and experts. One study used alternative measurements to assess the learners' skills [19]. An additional study explored the possibility of using a motion sensor to assess the skills of an operator [13].

Studies Comparing Different Training Methods

The remaining studies compared different methods of training. In general, these studies demonstrated that sim- 
Table 3. Overview of the simulators used in the included publications

\begin{tabular}{|c|c|c|c|c|}
\hline Simulator name & Simulator company & Type & $\begin{array}{l}\text { Simulated } \\
\text { procedure }\end{array}$ & $\begin{array}{l}\text { Publications including } \\
\text { this simulator }\end{array}$ \\
\hline Endoscopy AccuTouch ${ }^{\circledR}$ System & CAE Healthcare, Montreal, QC, Canada & VR & FB, EBUS & $\begin{array}{l}{[10,15-18,20,21,23,} \\
31,34,36-39]\end{array}$ \\
\hline Simbionix BRONCH Mentor ${ }^{\mathrm{TM}}$ & 3D Systems, Cleveland, OH, USA & VR & FB, EBUS & {$[13,14,33,35]$} \\
\hline PreOp endoscopy simulator & HT Medical Systems, Gaithersburg, MD, USA & VR & FB & {$[24,29,30,32]$} \\
\hline Orsim ${ }^{\circledR}$ bronchoscopy simulator & Airway Simulation Limited, Auckland, New Zealand & VR & $\mathrm{FB}$ & {$[16]$} \\
\hline NTUESC CBBS & National Taiwan University, Taipei, Taiwan, ROC & VR & $\mathrm{FB}$ & [26] \\
\hline Dexter ${ }^{\circledR}$ endoscopic dexterity trainer & Replicant ${ }^{\circledR}$ Medical Simulator Ltd., Wellington, New Zealand & model & $\mathrm{FB}$ & {$[27,28]$} \\
\hline Choose the hole & designed by Dr. Arthur Frederick David Cole & model & $\mathrm{FB}$ & [28] \\
\hline AirMan & Laerdal, Stavanger, Norway & manikin & $\mathrm{FB}$ & [27] \\
\hline Airway management trainer & Laerdal, Stavanger, Norway & manikin & $\mathrm{FB}$ & [32] \\
\hline $\begin{array}{l}\text { Model No. } 1815+\text { demonstration } \\
\text { model No. } 252500\end{array}$ & Sawbones, Pacific Research Laboratories USA & model & $\mathrm{FB}$ & {$[19,21]$} \\
\hline Cadaveric model & - & - & $\mathrm{FB}$ & {$[12,23,36]$} \\
\hline Constructed simulators & built by the authors & - & $\mathrm{FB}$ & {$[11,22,25]$} \\
\hline
\end{tabular}

NTUESC CBBS, National Taiwan University Endoscopic Simulation Collaborative Study Group Computer-Based Bronchoscopy Simulator; VR, virtual reality simulator; model, non-anatomical model simulator; manikin, anatomical simulator of synthetic material; FB, flexible bronchoscopy; EBUS, endobronchial ultrasound.

ulation-based training was an effective training method when participants were tested before and after an intervention $[27,29,31,32]$. In addition, they showed that the skills of simulation-trained participants were similar to those who received training based on the traditional apprenticeship model [20, 29, 31, 32]. Bjerrum et al. [10, 15] published 2 randomized studies on training methods: one explored the efficiency of dyad practice [15], and the other compared different distribution practices [10]. The conclusions of these studies were that both dyad practice and practice for only 1 day led to no significant differences in effectiveness when compared to individual practice and a distributed practice of 3 weeks, respectively. Four studies assessed participants' skills when performing procedures on patients (or in 1 case, on other participants) $[20,28,29,31]$ and, thus, showed that the acquired skills were transferable. Furthermore, Wahidi et al. [20] challenged the assumption that the learning curve of flexible bronchoscopy reaches a plateau after 50 bronchoscopies and, in fact, found that this transition occurred more often after 100 bronchoscopies.

\section{Endobronchial Ultrasound}

One publication explored a simulation-based test and proved its ability to differentiate between 4 groups of trainees with varying degrees of bronchoscopy and EBUS experience [39]. Two publications gathered validity evidence for assessment tools, and 1 focused on exploring which simulator metrics could reliably differentiate between experts and novices [35]. A randomized controlled

Simulation-Based Training in Flexible

Bronchoscopy and EBUS-TBNA trial [33] validated an assessment tool, the endobronchial ultrasound assessment tool (EBUSAT), which had been developed by the research group. This tool was used to assess the competency of participants trained according to the apprenticeship model as compared to those who received simulation-based training. The latter study group scored higher on the EBUSAT. Both the knowledge of anatomy and the biopsy techniques were assessed.

The remaining 4 publications focused on comparing different training methods. Two compared simulationbased training with both wet laboratory training and traditional apprenticeship training. These studies demonstrated that simulation-based training was equally effective as the other 2 approaches $[36,37]$. In another study, the authors reached the same conclusion when comparing physician- and respiratory therapist-proctored training [34]. Finally, Stather et al. [38] compared learning curves of trainees who had undergone simulation training with a second group who received clinical training. The authors found that the simulation-trained group acquired skills more rapidly than the other group.

Two studies used procedural performance on patients as an outcome measure, revealing that the skills taught on a simulator were transferable to a clinical setting $[33,37]$.

\section{Assessment}

If a study included an assessment of a participant's skill level, this was either based on simulator metrics $[10,14$, $15,18,26,30-32,34-36,38,39]$ or a test during which 1 or more raters (sometimes blinded) evaluated the par-

Respiration 2017;93:355-362

DOI: $10.1159 / 000464331$ 
ticipant's performance using an assessment tool [17, 19, $20,24,28,29,31-33,37]$. While outcome measures were most often quantitative and objective, some studies incorporated subjective evaluation (sometimes as the only outcome measure) $[11,12,14,18,21-23,25,26]$. Six studies included performance on patients or other participants when assessing the participants' skills $[20,28,29$, $31,33,37]$.

Of all the publications on flexible bronchoscopy, only a few included biopsies as an essential part of the operator assessment [16-18]. Two studies used the BSTAT during which the operator might be asked to perform a biopsy as 1 of a few standard tasks [20,24]. Finally, 2 studies included training in conventional TBNA but provided only subjective opinions regarding the simulators rather than an objective assessment of the operator performance [21, 22 ]. The remainder of the publications on flexible bronchoscopy studied diagnostic bronchoscopy only.

Moorthy et al. [30] found that none of the simulator metrics could differentiate novices from experts after the former group had performed 5 bronchoscopies on a simulator. Ost et al. [31] found that the metrics were not able to discriminate between intermediates and experts, while Colt et al. [32] found that novices performed equally well or even better than skilled physicians on some simulator metrics after practicing for a few hours. Furthermore, Chen et al. [26] found the simulator metrics to differentiate between participants with no bronchoscopy experience and experts but made no observation on other levels of expertise. Konge et al. [18] found that simulator metrics were too imprecise to assess the quality of a lymph node biopsy.

\section{Discussion}

Flexible bronchoscopy with biopsy and EBUS-TBNA are important tools for the diagnosis and staging of lung cancer and other diseases. These procedures should be performed with a high level of quality to maximize the likelihood of obtaining an optimal diagnostic yield, while simultaneously minimizing risks for the patient and the equipment. The ultimate intent with simulation-based training is to create the basis for an optimal treatment of the patient to improve their prognosis.

Cook and West [40] recommended caution when focusing on patient outcomes in research. It would be ideal to be able to measure the effect of the simulation-based education on the prognosis of the patient, but there are too many links from the training to the patient outcome to make this meaningful and possible. No included pub- lications used patient outcome to measure the effect of the simulation-based training. Instead, in some studies the participants' skills were ultimately assessed while performing the procedure on patients who underwent EBUSTBNA [33, 37] or flexible bronchoscopy [20, 28, 29, 31]. Using performance on patients as an outcome measure provides us with the assurance that the skills acquired when training on a simulator can be transferred to a clinical setting, which in turn brings us 1 step closer to our goal of providing the patient with the best care possible.

Most publications included in this review used simulator metrics as the basis for the assessment of participants. These metrics can only differentiate between complete novices and experts and should not be used to measure finer nuances of competence between these 2 extremes. An example of a simulator metric that is commonly used is "segments entered." Colt et al. [32] found that the novices entered more segments than more experienced physicians, Moorthy et al. [30] showed no difference between novices and experts after 5 simulated bronchoscopies, and Konge et al. [17] also found this metric to be of no value for the discrimination between skill levels. Apparently, novices learn to enter almost all segments after a short time of practice, but this skill is clinically irrelevant if they cannot identify which segment or anatomical structure they are visualizing. For EBUS-TBNA it is possible to use the metrics with caution [35].

Some of the publications assessed the participants with a non-blinded rater. This automatically lowers the level of evidence as the risk of bias is very high when raters are non-blinded [41].

The vast majority of the publications focused on teaching the anatomy, whereas only a few supplemented this with training in the biopsy procedure. A perfect biopsy technique does not make sense if the operator does not know where the biopsy was taken. Similarly, it does not make sense to know the anatomy if you are not able to take biopsies. Krogh et al. [16] and Konge et al. [17] used the same assessment method, which ensures a comprehensive rating not only because of the equal emphasis on both anatomy and biopsy taking, but also because of its ability to discriminate between varying degrees of experience.

Simulation-based training provides us with a great tool for learning procedures, in this case for flexible bronchoscopy with biopsy and EBUS-TBNA. There is, however, still a long way to go in establishing an effective curriculum for simulation-based training. An ideal training programme should include the following: directed self-regulated learning, distributed learning, and mastery learning $[42,43]$. Directed self-regulated learning, which provides
360

Respiration 2017;93:355-362

DOI: $10.1159 / 000464331$
Naur/Nilsson/Pietersen/Clementsen/ Konge 
the trainees with the chance to learn from their own experiences and mistakes, has been shown to be an effective learning method in simulation [44]. Bjerrum et al. [10] explored practice distribution, but only with flexible bronchoscopy, and found no significant differences between the 2 groups with regard to their subsequent performance on the simulator. This finding contradicts other studies which have demonstrated that distributing learning over a longer period of time proved highly efficient [45-47]. However, the study by Bjerrum et al. [10] used only the insensitive simulator metrics, which could explain the negative findings. Mastery learning, where the trainee must reach a certain level of competence before advancing to the next step, includes simulation-based tests with solid evidence of validity and is an essential part of simulationbased training [48]. Dyad practice, where 2 trainees practice together on the same simulator using the same time span as an individual would, was proved to be as effective as individual practice $[49,50]$. In 1 of our included studies [15], the dyad practice trainees subsequently performed as well as the individual trainees. This approach to training is, therefore, possible, even though it is less flexible because the 2 trainees must be available at the same time.

To the best of our knowledge, no studies on simulation-based training in oesophageal ultrasound-guided fine-needle aspiration (EUS-FNA) exist, though there is a significant need for research in this area. EBUS-TBNA and EUS-FNA complement each other $[1,51]$. The use of the EBUS endoscope in the oesophagus (EUS-B-FNA) is rapidly gaining acceptance [1]. It is, therefore, surprising that no virtual reality EUS-FNA simulator exists, while there are several EBUS simulators on the market (Table 3). Trainees have to practice on phantoms and patients. A recent national needs assessment study showed EUS-FNA to rank fourth on the list of technical skills that should be included in a simulation-based curriculum [52].

\section{Strengths and Limitations}

Notable strengths of our review are that it was conducted systematically by 2 independent reviewers and that the authors include experts in interventional pulmonology and simulation-based training. A limitation is that it was not possible to perform a meta-analysis due to the heterogeneity of the included studies.

\section{Conclusion and Recommendations}

Studies included in this review revealed that trainees receiving simulation-based training in flexible bronchoscopy and EBUS-TBNA acquired similar or better skills when compared to trainees with apprenticeship training. Simulation-based training is more efficient than apprenticeship training during the beginning of the learning curve because the patients are exposed to fewer risks due to inexperience of the operator, and it should thus be mandatory prior to performing procedures on patients. Evidence suggests that physical models (phantoms, etc.) and virtual reality simulators supplement each other, and similar skills can be taught by both modalities. Simulator metrics can be used with caution as an assessment of competence for EBUS-TBNA but should not be used for flexible bronchoscopy as they are too insensitive. Studies from other areas than bronchoscopy and EBUS-TBNA suggest that training could be optimally structured as directed self-regulated learning in a distributed training programme, which we therefore recommend for training in flexible bronchoscopy as well as EBUS. Finally, simulation-based training should be based on a mastery learning approach, during which simulator training continues until competency is achieved, as assessed by an expert rater (flexible bronchoscopy) and simulator metrics (EBUS).

\section{References}

1 Vilmann P, Clementsen PF, Colella S, et al: Combined endobronchial and esophageal endosonography for the diagnosis and staging of lung cancer: European Society of Gastrointestinal Endoscopy (ESGE) Guideline, in cooperation with the European Respiratory Society (ERS) and the European Society of Thoracic Surgeons (ESTS). Endoscopy 2015; 47:c1.

2 Kemp SV, El Batrawy SH, Harrison RN, et al: Learning curves for endobronchial ultrasound using cusum analysis. Thorax 2010;65: 534-538.
3 Jernlas B, Nyberger H, Ek L, et al: Diagnostic yield and efficacy of endobronchial ultrasound-guided transbronchial needle aspiration in mediastinal lymphadenopathy. Clin Respir J 2012;6:88-95.

4 Stather DR, MacEachern P, Chee A, et al: Trainee impact on procedural complications: an analysis of 967 consecutive flexible bronchoscopy procedures in an interventional pulmonology practice. Respiration 2013;85: 422-428.

5 Ziv A, Wolpe PR, Small SD, et al: Simulationbased medical education: an ethical imperative. Acad Med 2003;78:783-788.
6 Ouellette DR: The safety of bronchoscopy in a pulmonary fellowship program. Chest 2006; 130:1185-1190.

7 Ziv A, Ben-David S, Ziv M: Simulation based medical education: an opportunity to learn from errors. Med Teach 2005;27:193-199.

8 Cook DA, Hatala R, Brydges R, et al: Technology-enhanced simulation for health professions education: a systematic review and meta-analysis. JAMA 2011;306:978-988.

9 Moher D, Liberati A, Tetzlaff J, et al: Preferred reporting items for systematic reviews and meta-analyses: the PRISMA statement. Int J Surg 2010;8:336-341.
Simulation-Based Training in Flexible Bronchoscopy and EBUS-TBNA
Respiration 2017;93:355-362 DOI: $10.1159 / 000464331$ 
10 Bjerrum AS, Eika B, Charles P, et al: Distributed practice. The more the merrier? A randomised bronchoscopy simulation study. Med Educ Online 2016;21:30517.

11 Byrne T, Yong SA, Steinfort DP: Development and assessment of a low-cost 3D-printed airway model for bronchoscopy simulation training. J Bronchology Interv Pulmonol 2016;23:251-254.

12 Chen A, Machuzak M, Edell E, et al: Peripheral bronchoscopy training using a human cadaveric model and simulated tumor targets. J Bronchology Interv Pulmonol 2016;23:8386.

13 Colella S, Sondergaard Svendsen MB, Konge $\mathrm{L}$, et al: Assessment of competence in simulated flexible bronchoscopy using motion analysis. Respiration 2015;89:155-161.

14 Pastis NJ, Vanderbilt AA, Tanner NT, et al: Construct validity of the Simbionix BRONCH mentor simulator for essential bronchoscopic skills. J Bronchology Interv Pulmonol 2014; 21:314-321.

15 Bjerrum AS, Eika B, Charles P, et al: Dyad practice is efficient practice: a randomised bronchoscopy simulation study. Med Educ 2014;48:705-712.

16 Krogh CL, Konge L, Bjurstrom J, et al: Training on a new, portable, simple simulator transfers to performance of complex bronchoscopy procedures. Clin Respir J 2013;7: 237-244.

17 Konge L, Arendrup H, von Buchwald C, et al: Using performance in multiple simulated scenarios to assess bronchoscopy skills. Respiration 2011;81:483-490.

18 Konge L, Arendrup H, von Buchwald C, et al: Virtual reality simulation of basic pulmonary procedures. J Bronchology Interv Pulmonol 2011;18:38-41.

19 Colt HG, Davoudi M, Murgu S, et al: Measuring learning gain during a one-day introductory bronchoscopy course. Surg Endosc 2011; 25:207-216.

20 Wahidi MM, Silvestri GA, Coakley RD, et al: A prospective multicenter study of competency metrics and educational interventions in the learning of bronchoscopy among new pulmonary fellows. Chest 2010;137:10401049.

21 Davoudi M, Wahidi MM, Zamanian Rohani $\mathrm{N}$, et al: Comparative effectiveness of low- and high-fidelity bronchoscopy simulation for training in conventional transbronchial needle aspiration and user preferences. Respiration 2010;80:327-334.

22 Goldberg R, Colt HG, Davoudi M, et al: Realistic and affordable lo-fidelity model for learning bronchoscopic transbronchial needle aspiration. Surg Endosc 2009;23:20472052.
23 Deutsch ES, Christenson T, Curry J, et al: Multimodality education for airway endoscopy skill development. Ann Otol Rhinol Laryngol 2009;118:81-86.

24 Davoudi M, Osann K, Colt HG: Validation of two instruments to assess technical bronchoscopic skill using virtual reality simulation. Respiration 2008;76:92-101.

25 Di Domenico S, Simonassi C, Chessa L: Inexpensive anatomical trainer for bronchoscopy. Interact Cardiovasc Thorac Surg 2007;6:567569.

26 Chen JS, Hsu HH, Lai IR, et al: Validation of a computer-based bronchoscopy simulator developed in Taiwan. J Formos Med Assoc 2006;105:569-576.

27 Agrò F, Sena F, Lobo E, et al: The Dexter Endoscopic Dexterity Trainer improves fibreoptic bronchoscopy skills: preliminary observations. Can J Anaesth 2005;52:215-216.

28 Martin KM, Larsen PD, Segal R, et al: Effective nonanatomical endoscopy training produces clinical airway endoscopy proficiency. Anesth Analg 2004;99:938-944; table of contents.

29 Blum MG, Powers TW, Sundaresan S: Bronchoscopy simulator effectively prepares junior residents to competently perform basic clinical bronchoscopy. Ann Thorac Surg 2004;78:287-291; discussion 287-291.

30 Moorthy K, Smith S, Brown T, et al: Evaluation of virtual reality bronchoscopy as a learning and assessment tool. Respiration 2003;70: 195-199.

31 Ost D, DeRosiers A, Britt EJ, et al: Assessment of a bronchoscopy simulator. Am J Respir Crit Care Med 2001;164:2248-2255.

32 Colt HG, Crawford SW, Galbraith O 3rd: Virtual reality bronchoscopy simulation: a revolution in procedural training. Chest 2001;120: 1333-1339.

33 Konge L, Clementsen PF, Ringsted C, et al: Simulator training for endobronchial ultrasound: a randomised controlled trial. Eur Respir J 2015;46:1140-1149.

34 Stather DR, Chee A, Maceachern P, et al: Evaluation of a novel method of teaching endobronchial ultrasound: physician- versus respiratory therapist-proctored simulation training. Can Respir J 2013;20:243-247.

35 Konge L, Annema J, Clementsen P, et al: Using virtual-reality simulation to assess performance in endobronchial ultrasound. Respiration 2013;86:59-65.

36 Stather DR, MacEachern P, Chee A, et al: Wet laboratory versus computer simulation for learning endobronchial ultrasound: a randomized trial. Can Respir J 2012;19:325-330.

37 Stather DR, MacEachern P, Chee A, et al: Evaluation of clinical endobronchial ultrasound skills following clinical versus simulation training. Respirology 2012;17:291-299.

38 Stather DR, Maceachern P, Rimmer K, et al: Assessment and learning curve evaluation of endobronchial ultrasound skills following simulation and clinical training. Respirology 2011;16:698-704.
39 Stather DR, Maceachern P, Rimmer K, et al: Validation of an endobronchial ultrasound simulator: differentiating operator skill level. Respiration 2011;81:325-332.

40 Cook DA, West CP: Perspective: reconsidering the focus on "outcomes research" in medical education: a cautionary note. Acad Med 2013;88:162-167.

41 van Hove PD, Tuijthof GJ, Verdaasdonk EG, et al: Objective assessment of technical surgical skills. Br J Surg 2010;97:972-987.

42 Farr A, Clementsen P, Herth F, et al: Endobronchial ultrasound: launch of an ERS structured training programme. Breathe 2016;12: 217-220.

43 Cook DA, Hamstra SJ, Brydges R, et al: Comparative effectiveness of instructional design features in simulation-based education: systematic review and meta-analysis. Med Teach 2013;35:e867-e898.

44 Brydges R, Nair P, Ma I, et al: Directed selfregulated learning versus instructor-regulated learning in simulation training. Med Educ 2012;46:648-656.

45 Andersen SA, Konge L, Caye-Thomasen P, et al: Learning curves of virtual mastoidectomy in distributed and massed practice. JAMA Otolaryngol Head Neck Surg 2015;141:913918.

46 Andersen SA, Mikkelsen PT, Konge L, et al: Cognitive load in distributed and massed practice in virtual reality mastoidectomy simulation. Laryngoscope 2016;126:E74-E79.

47 Moulton CA, Dubrowski A, Macrae H, et al: Teaching surgical skills: what kind of practice makes perfect?: A randomized, controlled trial. Ann Surg 2006;244:400-409.

48 McGaghie WC, Issenberg SB, Barsuk JH, et al: A critical review of simulation-based mastery learning with translational outcomes. Med Educ 2014;48:375-385.

49 Rader SB, Henriksen AH, Butrymovich V, et al: A study of the effect of dyad practice versus that of individual practice on simulationbased complex skills learning and of students' perceptions of how and why dyad practice contributes to learning. Acad Med 2014;89: 1287-1294.

50 Tolsgaard MG, Madsen ME, Ringsted C, et al: The effect of dyad versus individual simulation-based ultrasound training on skills transfer. Med Educ 2015;49:286-295.

51 Vilmann P, Clementsen PF: Combined EUS and EBUS are complementary methods in lung cancer staging: do not forget the esophagus. Endosc Int Open 2015;3:E300-E301.

52 Nayahangan LJ, Clementsen PF, Paltved C, et al: Identifying technical procedures in pulmonary medicine that should be integrated in a simulation-based curriculum: a national general needs assessment. Respiration 2016;91: 517-522. 